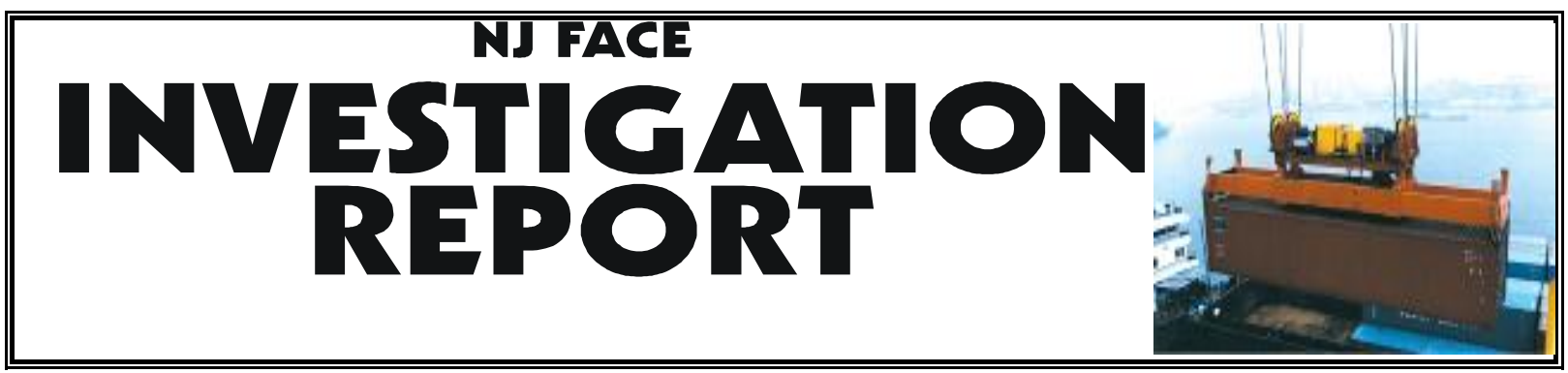

Fatality Assessment \& Control Evaluation Project

FACE 08-NJ-012

November 10, 2009

\title{
Entrapment in an Intermodal Cargo-Container Spreader Kills Worker at Seaport Terminal
}

A worker was killed when his head was crushed between structural beams of an intermodal cargo-container spreader as it was being closed during the lubrication of the guide rails. A crew of four employees prepared the spreader for use, with one employee working the crane and the three others lubricating the guide rails with a petroleum-based aerosol spray. The employees lubricating the guide rails had to be within the moving parts of the spreader in order to reach certain areas of the guide rails. At the time of the incident, there was no written standard operating procedure or employee training for the spreader guide-rail lubrication procedure.

NJ FACE investigators recommend following these safety guidelines to prevent similar incidents:

- Lubrication procedures for intermodal cargo-container spreaders should be designed so that employees can perform this task without reaching into moving parts of the spreader. These procedures may require both specific tools and welldesigned work practices.

- Standard Operating Procedures (SOPs) and training specific to the maintenance and hazards of spreaders should be developed and provided to all employees who handle the loading and off-loading of intermodal cargo containers. These SOPs and training should include information on hazards and safe work practices.

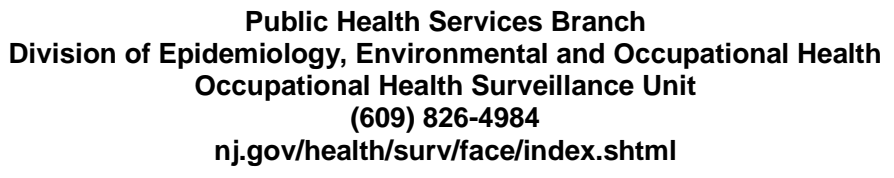


- Ground crews working with intermodal container-cargo spreaders should have the ability to operate the spreader, have panic buttons and interrupt switches available for use in the event of an emergency, and at least one ground crew member should act as a spotter.

- Communication among all workers must be effective and include properly operating voice communication systems. Communications must be real-time and allow for employees to communicate from the location where they are working.

- Employers should investigate equipping the mobile equipment, such as the cargocontainer or the crane, with additional visual or sensing devices to enhance the operator's ability to detect the presence of workers on foot near the spreader. This includes technologies such as cameras, radar, and/or sonar to alert the operator to the presence of workers in "blind areas," as well as tag-based warning systems, which can detect workers wearing tags.

- Employers should conduct a job hazard analysis of all work activities with the participation of the workers. 


\section{INTRODUCTION}

During the winter of 2009, a New Jersey Office of Public Employees Occupational Safety and Health (PEOSH) officer notified NJ FACE staff of the death of a 56-year-old public employee who was killed after being crushed inside an intermodal cargo container spreader. A NJ FACE investigator contacted the employer and arranged to conduct an investigation.

The victim was a foreign-born white male who spoke Polish as his first language, and had been living in the United States for over 20 years and also spoke English. Employee health and safety training, as well as job training, was conducted on site by the employer.

\section{INVESTIGATION}

The incident occurred in early morning hours as a work crew began to prepare the crane and spreader to unload intermodal containerized cargo. It was a cold and dry winter day, and the dock was reported to have had sufficient lighting; the exact lighting conditions under the spreader at the time of the incident are unknown. Four employees were assigned to this job, which included one employee operating the crane and the other three employees working on the ground. All four men on the work crew were classified as crane operators by the employer and

were qualified to operate the crane. The crew began working at 5:00 am to prepare the crane and spreader for the off-loading of cargo scheduled for 7:00 am. The incident occurred at approximately 5:45 am. The crew had already attached the spreader to the crane and was in the process of lubricating the guide rails.

A large crane was used to handle the cargo containers that were stacked on the deck of cargo ships. Attached to the crane was a spreader, a large device designed to connect to cargo containers at their corners with locking devices (see Figures 1 and 2). 
Figure 1 - Crane and spreader in use at the site of the incident.

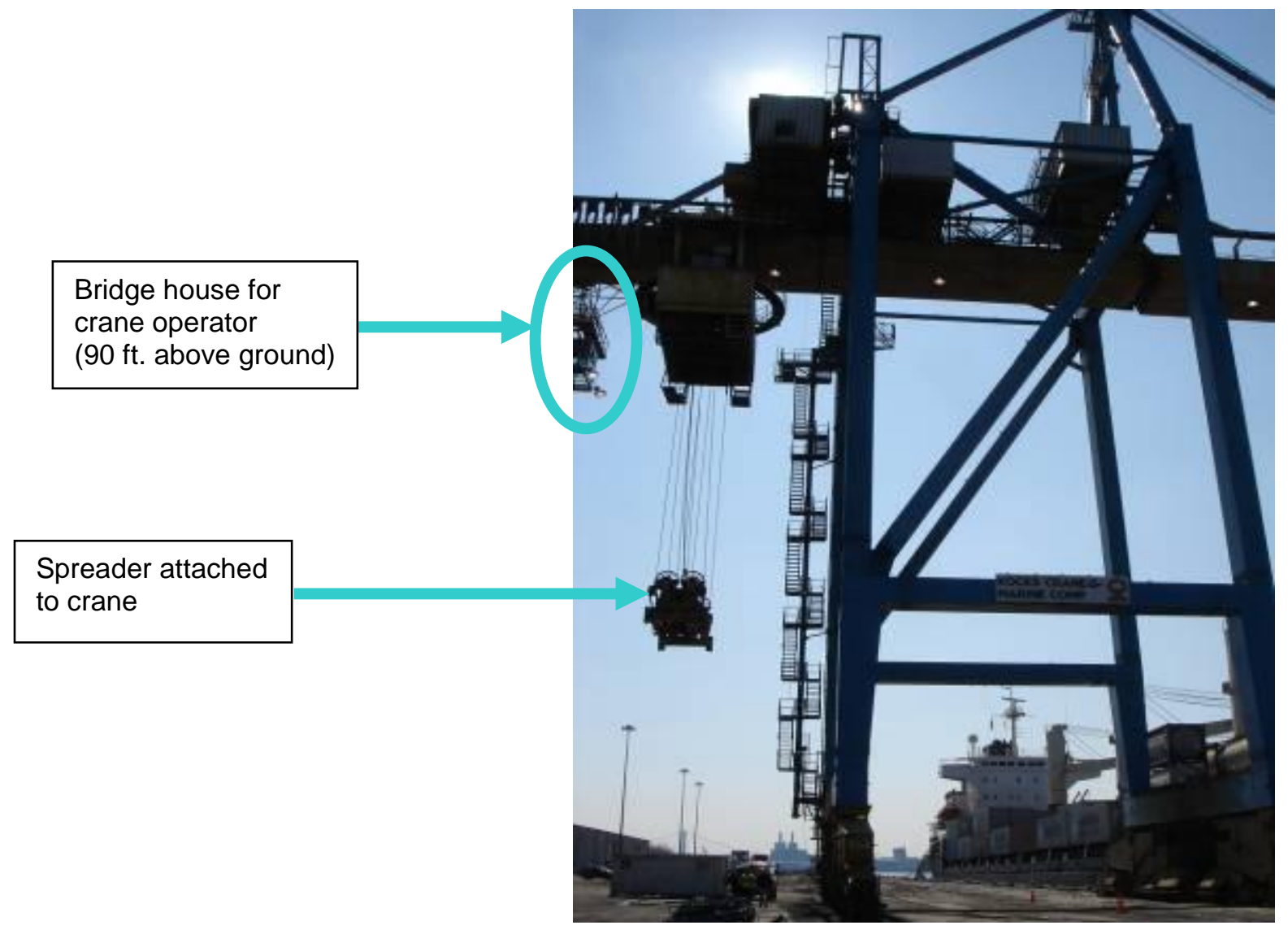

Figure 2 - The spreader involved in the incident lowered to the approximate height for lubrication of the guide rails.

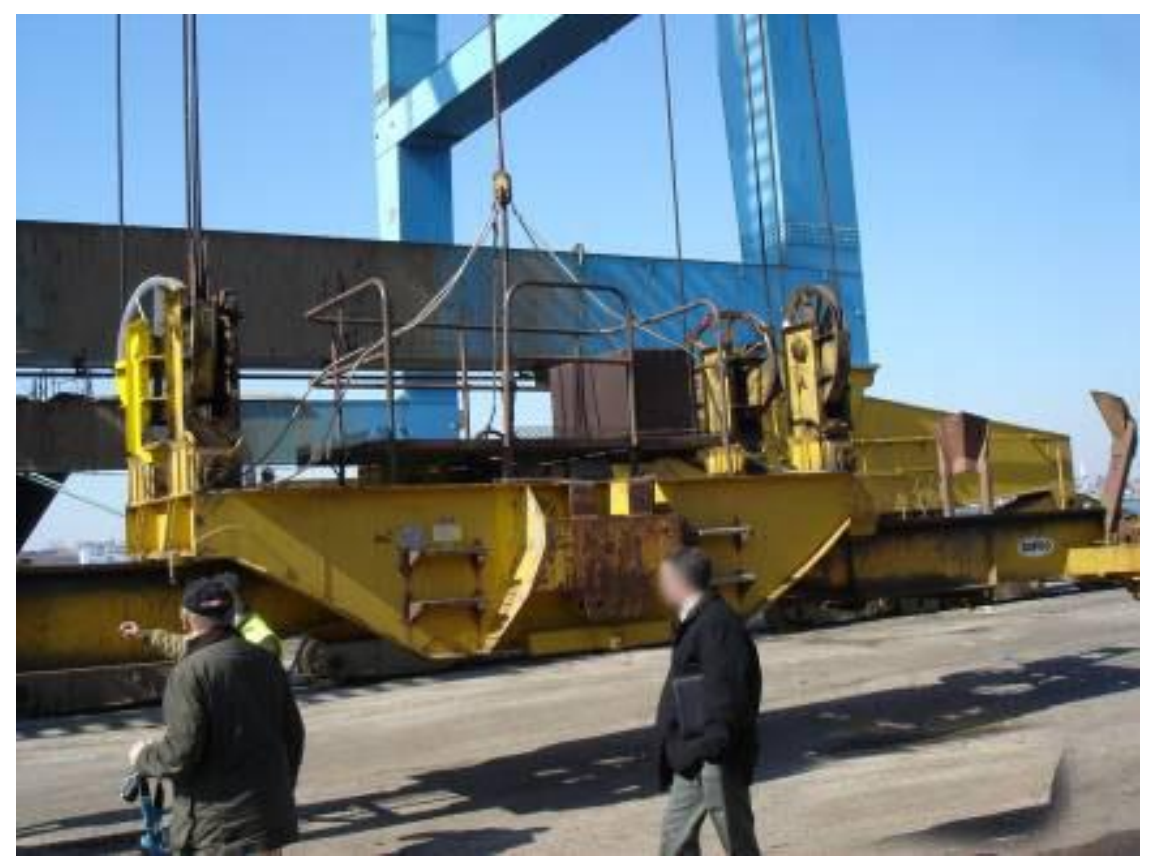


The guide rails must be lubricated to reduce wear and to allow the telescoping sections of the spreader to move easily. In this seaport, the guide rails had to be lubricated before each use of the spreader and, occasionally, in the middle of a work shift. The lubricant used was a petroleum-based compound that was sprayed onto the guide rails from a hand-held aerosol can. Employees used two to three aerosol cans each time the guide rails were lubricated and reported that the lubrication process was learned on the job through hands-on experience. There were no written standard operating procedures, training, or hazard assessment for this work activity.

The guide-rail lubrication procedure involved a crane operator lifting the spreader to approximately five feet above the ground so that the spreader was at "eye level" for the three employees stationed on the ground. The crane operator then opened and closed the spreader while the three other workers walked under the spreader and sprayed lubricant on the guide rails. When the telescoping sections of the spreader became stuck, the ground crew used hand signals to tell the crane operator to strike the spreader against the pavement in an attempt to knock the stuck section free.

On the day of the incident, the decedent was spraying lubricant onto the guide rails when his head became positioned between two support beams under the two telescoping sections of the spreader. His head was crushed when the support beams slid past each other as the spreader was being closed (Figure 3).

Figure 3 - Entrapment point where employee's head was crushed.

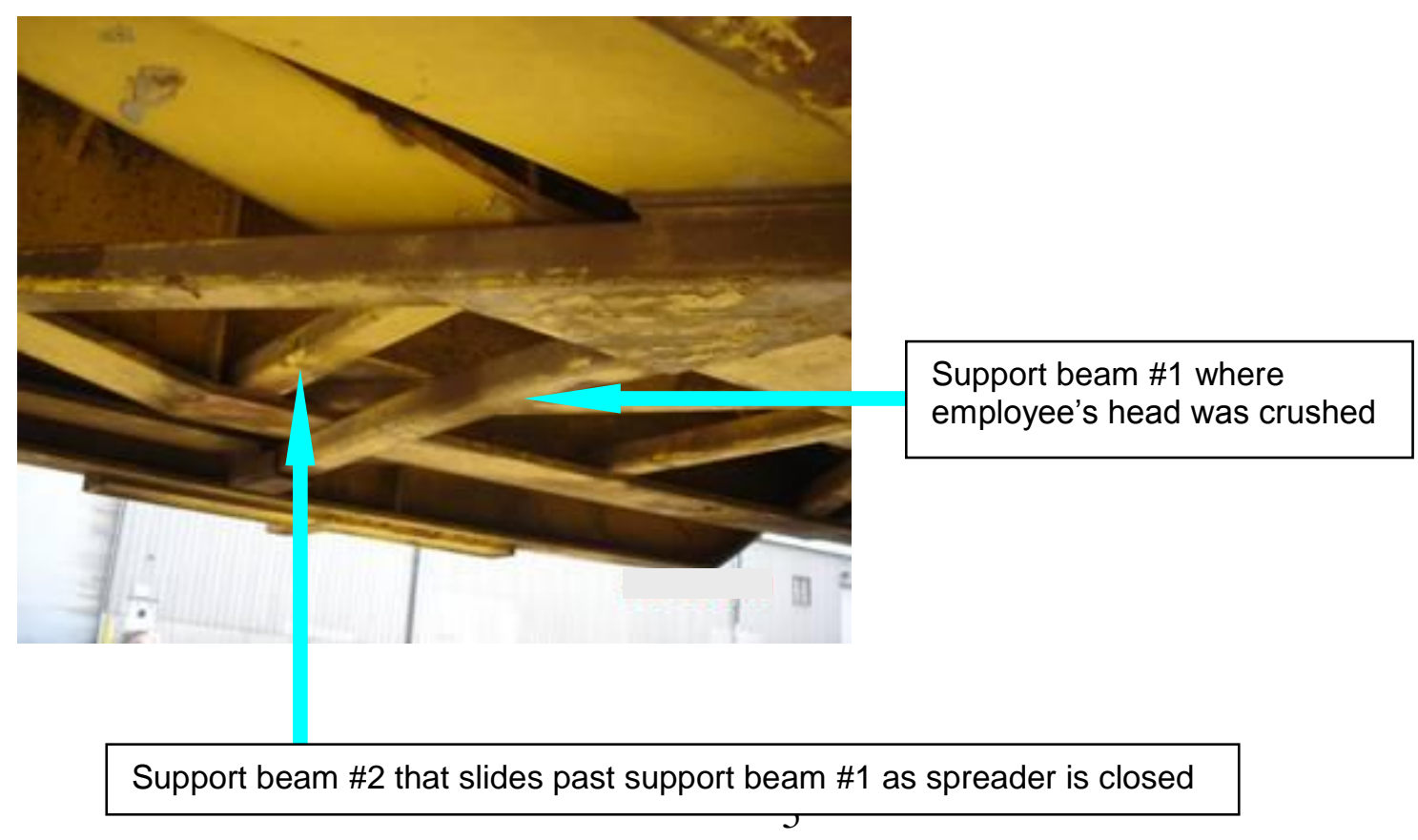


The guide rails of the telescoping sections slide through guide blocks in the middle section and allow the sections of the spreader to maintain alignment when being opened and closed. In addition, the telescoping sections of the spreader have structural support beams on the underside of the spreader (see Figure 4).

Figure 4 - Guide rails of the expandable section, which are lubricated, and the structural support beams on the underside of the spreader.

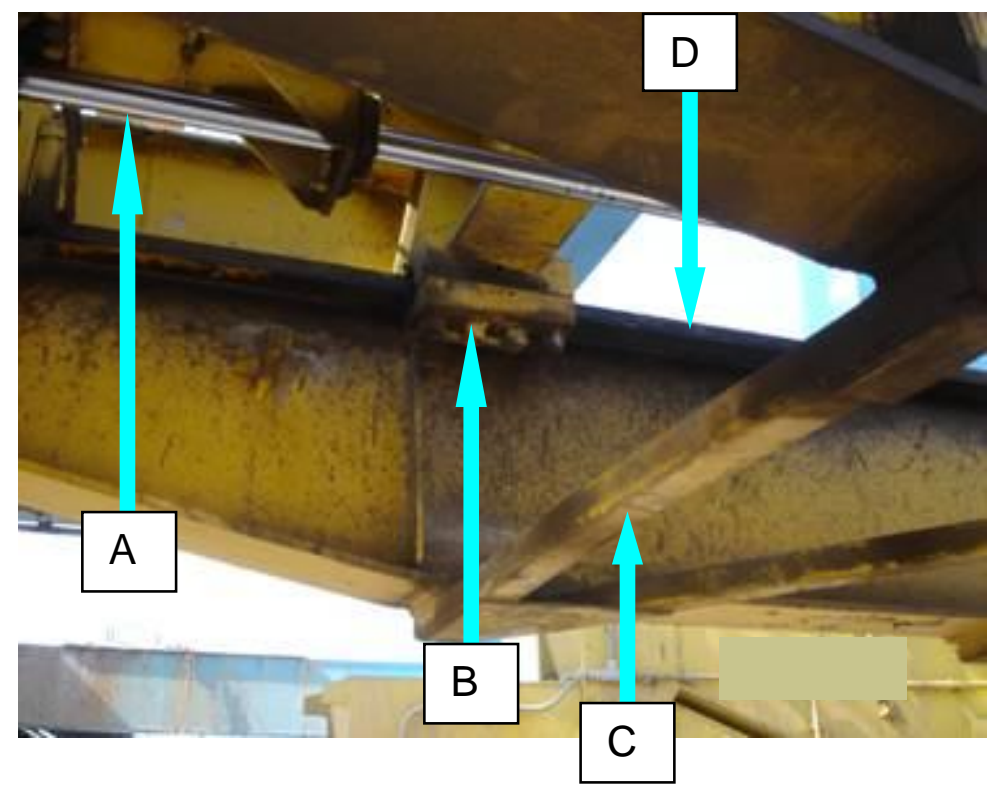

$A=$ hydraulic piston used to open and close telescoping sections of spreader

$\mathrm{B}=$ guide block of center spreader section

C = structural support beam

$\mathrm{D}=$ top side of telescoping section guide rail

The worker operating the crane was unaware that an employee was injured because he could not see the employee under the spreader from the crane bridge house, which was 90 feet above the ground. In addition, clear wireless communications via two-way radio was not possible at this job location due to constant radiofrequency interference on site, according to port management and the employees interviewed by the FACE investigation team. The crane operator continued moving the spreader after the injury occurred because he was unaware that an employee was injured. He became aware of the injury when he saw blood flowing out from underneath the spreader and saw the other ground crew members frantically waving at him from below. Emergency services was called and the injured employee was pronounced dead at the scene as a result of severe blunt force head trauma. 


\section{RECOMMENDATIONS/DISCUSSIONS}

\section{Recommendation \#1: Lubrication procedures for intermodal cargo-container spreaders}

should be designed so that employees can perform this task without reaching into moving parts of the spreader. These procedures may require both specific tools and well designed work practices.

Discussion: Work practices for the lubrication of spreaders should be designed to eliminate any need for workers to reach into moving parts of the spreader. For example, in this incident the workers accessed the guide rail surfaces by standing under the spreader while it was freely suspended above the ground and reached upwards into the moving sections of the spreader to apply lubricant. This practice allowed for several potential hazards, including the possibility of the crane operator lowering the spreader onto an employee working underneath, the spreader falling onto the employee in the event of an uncontrolled release, and employees becoming entrapped within the spreader as they reach upwards. This procedure allows for employees to misjudge where they are in relation to the spreader because the height of the spreader above the ground varies each time the spreader is positioned for lubrication and because there is no immediate reference point for the employees working under the spreader.

Tools specifically designed to help workers apply lubricant without reaching into the spreader should be used. FACE investigators observed mechanics reaching into the spreader because they were using hand-held aerosol cans to apply lubricant. This could be prevented by using cans fitted with flexible extension wands to apply the lubricant, thereby precluding the possibility of workers positioning body parts between moving sections of the spreader (See Figure 5). In addition, other lubricant products that might not require as frequent applications or reaching into the spreader should be considered.

NJ FACE also recommends that manufacturers move to designing and producing fully electric spreaders which are driven completely electrically and do not need any lubrication. These spreaders would effectively eliminate the hazard associated with this type of incident. 
Figure 5. The use of extension wands for lubricant application.

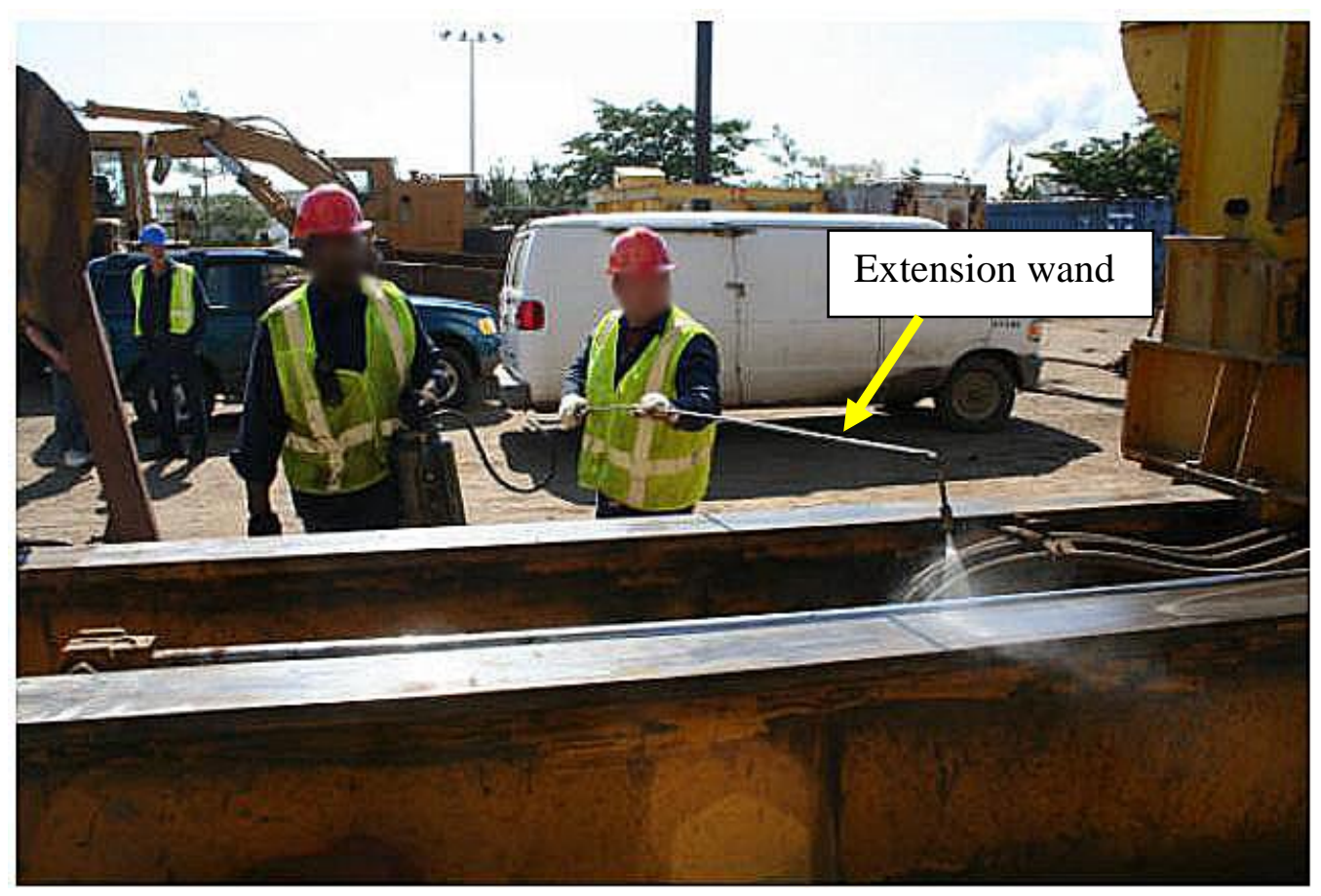

NJ FACE also recommends that the control of hazardous energy should be considered.

According to 29 CFR 1917.151(b)(7) (Marine Terminals, Related Terminal Operations and equipment): The power supply to machines shall be turned off, locked out, and tagged out during repair, adjustment or servicing. Therefore, the container spreader should be de-energized while being lubricated. ${ }^{1}$

Recommendation \#2: Standard Operating Procedures (SOPs) and training specific to the maintenance and hazards of spreaders should be developed and provided to all employees who handle the loading and off-loading of intermodal cargo containers. These SOPs and training should include information on possible associated hazards and safe work practices.

Discussion: This facility did not have any formal SOP or training regarding maintenance of the spreader at the time of the incident. As a result, employees may not have been aware of the hazards associated with the activity that resulted in the fatal injury. The SOP and training should contain practical health and safety protocols and focus on the identification and mitigation of hazards in all relevant job tasks. 
Since the time of the incident, the employer developed and implemented a very specific SOP that thoroughly outlines the lubrication procedure. The SOP includes personal protective equipment requirements (safety vests, hardhats, chemical goggles, gloves), two-way radio communication, the development of a limited access zone around the spreader lubrication area, and a detailed protocol regarding the lubrication process. Two critical steps in the SOP's delineation of the lubrication process are: 1) at no time will the ground crew be underneath the spreader, 2) at no time will any chemical be applied to the spreader when it is in motion.

Recommendation \#3: Ground crew working with intermodal container-cargo spreaders should have the ability to operate the spreader, have panic buttons and interrupt switches available for use in the event of an emergency, and at least one ground crew member should act as a spotter.

A significant hazard observed by FACE investigators was the lack of awareness of the crane operator to ground conditions and the simultaneous inability of the ground workers, who are most at risk of injury, to control the mechanical energy of the spreader. This situation could be avoided if the ground crew could operate the spreader from controls accessible at ground level.

In this incident, it also may have been beneficial if employees on the ground had access to a hand-held panic button (or "kill switch") with an emergency interrupt switch that shut the spreader down. An engine-kill switch mounted where it is easily accessible, visible and clearly labeled, would allow a quick method of stopping the spreader.

Fellow ground crew members of the decedent did not observe the actual fatal injury because they were lubricating other sections of the guide rails. They only became aware of the fatal injury when they heard the decedent drop his aerosol can and fall to the ground. Ground crews should utilize a "spotter" who would simply stand back and look for any potential hazard during maintenance of the spreader. In this case, the spotter might recognize hazards sooner than other workers and initiate corrective action quickly.

Recommendation \#4: Communication among all workers must be effective and include properly operating voice communication systems. Communications must be real-time and allow for employees to communicate from the location where they are working. 
Discussion: In this incident, the ground crew was unable to quickly communicate with the crane operator due to deficiencies in the communication system, as evidenced by use of hand signals. NJ FACE recommends that effective real-time communication such as two-way radio should be employed at all times. If audio communication (at least) is not available, job tasks that involve the lubrication of the spreader should stop.

Recommendation \#5: Employers should investigate equipping the mobile equipment, such as the cargo-container or the crane, with additional visual or sensing devices to enhance the operator's ability to detect the presence of workers on foot near the spreader. This includes technologies such as cameras, radar, and/or sonar to alert the operator to the presence of workers in "blind areas," as well as tag-based warning systems, which can detect workers wearing tags.

Discussion: A variety of vision enhancement and/or object and personnel detection systems are available that can help vehicle and mobile equipment operators detect the presence of people or objects in the equipment's blind area. Strategically mounted video cameras could provide the operator with a clear view of the blind area around their equipment. Many of these camera systems are currently in use in both construction and non-construction applications. NIOSH has conducted research on a number of these systems. ${ }^{2-5}$

Currently, many commercial and personal vehicles are equipped with object proximity sensors that sound an alarm and, in some cases, have visual indicators to alert the driver when an object or person is near the vehicle. It is recommended that, when new trucks and equipment are purchased, visual and/or object sensing devices should be purchased as well. These sensing devices can also be installed on older trucks and equipment. In this incident, the ground crew was unable to quickly communicate with the crane operator due to deficiencies in the communication system.

Recommendation \#6: Employers should conduct a job hazard analysis of all work activities with the participation of the workers.

Discussion: To prevent incidents such as this, NJ FACE recommends that employers conduct a job hazard analysis of all work areas and job tasks with the assistance of the employees. A job hazard analysis is a procedure that breaks down a job or task into specific steps, analyzes each step for specific hazards, and uses this information to develop safe work procedures to eliminate or reduce those hazards. This process begins by reviewing the work activities that the employee 
is responsible for and the equipment that is needed. Each task is further examined for mechanical, electrical, chemical, or any other hazard that the worker may encounter. The results of the analysis can be used to design or modify the written standard operating procedures for the job. Additional information is available in the publication, Job Hazard Analysis, which is available on the federal OSHA Web site at www.osha.gov/Publications/osha3071.pdf. ${ }^{6}$ 


\section{APPENDIX}

\section{RECOMMENDED RESOURCES}

It is essential that employers obtain accurate information on health, safety, and applicable OSHA standards. NJ FACE recommends the following sources of information which can help both employers and employees:

\section{U.S. Department of Labor, Occupational Safety \& Health Administration (OSHA)}

Federal OSHA can provide information on safety and health standards on request. OSHA has several offices in New Jersey that cover the following counties:

Hunterdon, Middlesex, Somerset, Union, and Warren counties. 732-750-3270

留 Essex, Hudson, Morris, and Sussex counties 973-263-1003

Bergen and Passaic counties. 201-288-1700

㯊 Atlantic, Burlington, Cape May, Camden, Cumberland, Gloucester, Mercer, Monmouth, Ocean, and Salem counties $.856-757-5181$

Web site: www.osha.gov

\section{New Jersey Public Employees Occupational Safety and Health (PEOSH) Program}

The PEOSH Act covers all NJ state, county, and municipal employees. Two state departments administer the Act; the NJ Department of Labor and Workforce Development (NJDLWD) which investigates safety hazards and the NJ Department of Health and Senior Services (NJDHSS) which investigates health hazards. PEOSH has information that may also benefit private employers.

NJDLWD, Office of Public Employees Safety

留 Telephone: 609-633-3896

Web site: www.nj.gov/labor/lsse/lspeosh.html

NJDHSS, Public Employees Occupational Safety \& Health Program

捅 Telephone: 609-984-1863

品 Web site: www.nj.gov/health/peosh

On-site Consultation for Public Employers

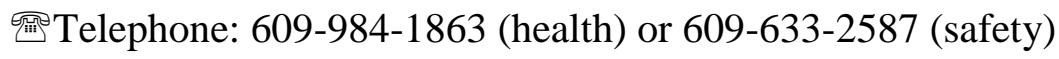

$\square$ Web site: www.state.nj.us/health/eoh/peoshweb/peoshcon.htm 
New Jersey Department of Labor and Workforce Development, Occupational Safety and Health On-Site Consultation Program

This program provides free advice to private businesses on improving safety and health in the workplace and complying with OSHA standards.

留 Telephone: 609-984-0785

Web site: www.nj.gov/labor/lsse/lsonsite.html

\section{New Jersey State Safety Council}

The New Jersey State Safety Council provides a variety of courses on work-related safety. There is a charge for the seminars.

䙹Telephone: 908-272-7712.

Web site: $w w w . n j s a f e t y . o r g$

\section{Internet Resources}

Other useful Internet sites for occupational safety and health information:

- $\mathrm{CDC} / \mathrm{NIOSH}-w w w . c d c . g o v / n i o s h$

- USDOL Employment Laws Assistance for Workers and Small Businesses www.dol.gov/elaws

- National Safety Council - www.nsc.org

- NJDHSS FACE reports - www.nj.gov/health/surv/face/index.shtml

- $\mathrm{CDC} / \mathrm{NIOSH}$ FACE - www.cdc.gov/niosh/face/faceweb.html

- OSHA - www.osha.gov

- ANSI - www.ansi.org

\section{REFERENCES}

1. 49 CFR 1917 Marine Terminals, Subpart G-Related Terminal Operations and Equipment, 151 Machine Guarding, (b)(7) The power supply to machines shall be turned off, locked out, and tagged out during repair, adjustment, or servicing.

2. NIOSH [2007]. Recommendations for evaluating and implementing proximity warning systems on surface mining equipment. Cincinnati, OH: U.S. Department of Health and Human Services, Centers for Disease Control and Prevention, National Institute for Occupational Safety and Health, NIOSH Publication 2007-146

[http://www.cdc.gov/niosh/mining/pubs/pubreference/outputid2480.htm].

3. Fosbroke DE [2004]. NIOSH reports studies on heavy equipment blind spots and internal traffic control. Unpublished paper presented at the 2004 Roadway Work Zone Safety \& Health 
Conference, Baltimore

[http://www.workzonesafety.org/files/documents/news_events/wz_conference_2004/

heavy_equipment.pdf].

4. Ruff T [2006]. Evaluation of a radar-based proximity warning system for off-highway dump trucks. Accid Anal Prev 38:92-98.

5. Ruff T [2003]. Report of Investigations RI 9660. Evaluation of systems to monitor blind areas behind trucks used in road construction and maintenance: phase 1. By Todd M. Ruff. Cincinnati, OH: U.S. Department of Health and Human Services, Centers for Disease Control and

Prevention, National Institute for Occupational Safety and Health, NIOSH Publication 2003-113.

6. Job Hazard Analysis. US Department of Labor Publication \# OSHA-3071, 1998 (revised). USDOL, OSHA Publications, PO Box 37535, Washington DC 20013-7535 


\section{Fatality Assessment and Control Evaluation (FACE) Project Investigation \# 08-NJ-012}

Staff members of the New Jersey Department of Health perform FACE investigations when there is a report of a targeted work-related fatal injury. The goal of FACE is to prevent fatal work injuries by studying the work environment, the worker, the task, the tools the worker was using, the energy exchange resulting in the fatal injury, and the role of management in controlling how these factors interact. FACE gathers information from multiple sources that may include interviews of employers, workers, and other investigators; examination of the fatality site and related equipment; and reviewing OSHA, police, and medical examiner reports, employer safety procedures, and training plans. The FACE program does not determine fault or place blame on employers or individual workers. Findings are summarized in narrative investigation reports that include recommendations for preventing similar events. All names and other identifiers are removed from FACE reports and other data to protect the confidentiality of those who participate in the program.

NIOSH-funded state-based FACE Programs include: California, Iowa, Kentucky, Massachusetts, Michigan, New Jersey, New York, Oregon, and Washington. Please visit the NJ FACE Web site at http://www.nj.gov/health/surv/face/index.shtml or the CDC/NIOSH FACE Web site at http://www.cdc.gov/niosh/face/ for more information.

The NJ FACE Project is supported by Cooperative Agreement \# 1 U60 OH0345-01 from the Centers for Disease Control and Prevention (CDC). The contents of this report are solely the responsibility of the authors and do not necessarily represent the official views of the CDC.

Daniel Lefkowitz, PhD, MS

FACE Project Coordinator

Environmental and Occupational Health

Surveillance Program
Jerald A. Fagliano, MPH, PhD

Health Science Specialist

Environmental and Occupational Health

Surveillance Program

Margaret Lumia, PhD, MPH

Principal Investigator

Environmental and Occupational Health

Surveillance Program

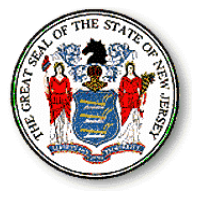

Public Health Services Branch

Division of Epidemiology, Environmental and Occupational Health

Occupational Health Surveillance Unit

(609) 826-4984

nj.gov/health/surv/face/index.shtml 